\title{
The Analysis on the Sensitivity of Geogrid Reinforcement Factors in Mine-Tailing Slopes
}

\author{
Xiaolin Lei, Chunming Qi ${ }^{*}$, Chunlong Nie and Fan Yang \\ School of Civil Engineering, University of South China, Hengyang, Hunan, China \\ *Corresponding author
}

\begin{abstract}
In order to find out the sensitivity of reinforcement factors that influences the geogrid reinforcement on slope stability of mine tailings, this paper designs the test according to orthogonal method. By choosing laying length $(L)$, laying distance (D), laying angle ( $\theta)$, tensile strength (T) and geogrid modulus (E) as influential factors and adopting the $\mathrm{L}_{25}\left(5^{6}\right)$ orthogonal table for 25-group scheme arrangement, this test tries to get corresponding safety factor $(F)$ of the reinforced slope through the strength-shear method with finite elements and make analysis on both the sensitivity and the significance of all available factors separately via variance analysis. The results show the sensitivity of all influential factors on stability and safety factor as follow in order of most to least: laying distance (D), tensile strength (T), geogrid modulus $(E)$, laying length $(L)$, laying angle $(\theta)$. the remarkable test show that laying distance (D) and tensile strength $(T)$ both have very remarkable influence and geogrid modulus $(E)$ comes second, while laying length $(L)$ only shows a little and laying angle $(\theta)$ little.
\end{abstract}

Keywords-geogrid; mine tailing; slope stability; finite elements; variance analysis

\section{RESEARCH BACKGROUND}

The mine-tailing ponds are one of the indispensable and important facilities for mine industry, and it is a major artificial danger source with high potential energy. Accidents happening beside mine-tailing slopes will cause mine loss and environmental pollution, etc. Seriously, it will pose a huge threat to the residents living in the downstream in terms of their life and property safety [1, 2, 3, 7]. Strikingly, it is paramount for mining enterprises in guaranteeing their normal operation and surrounding ecological environment to improve the safety and stability of mine-tailing slopes. Wei Fa-zheng successfully and effectively enhanced the safety and stability of mine-tailing reservoirs by laying high-strength geogrid in dam body, burying soft-typed water pipe and other measures together[1]; Wei Zuo-an and other researchers proposed to reinforce mine-tailing dams by adopting the terminal scroll-type geogrid, which turned out effective in dam's stability enhancement [2]. Zhao Yi-shu and others carried out a model test study on the damage to the doom of the reinforced mine-tailing dams, showing that the blockade effects accompanying the damage process of the reinforced belt could effectively intensify the steadiness of dams [3]. Because of the complex mechanism of soil reinforcement and numerous factors influencing reinforcement effect, it is greatly instructive for engineering-project practices to ensure the main influencing factors.

There are two common analysis methods for test results calculated by orthogonal experimental method: range analysis and variance analysis. This paper will employ the variance analysis method suitable for sensitivity analysis and significance test to determine the dominant factors that influence the stability of reinforced mine-tailing slopes [4]. The design of the reinforcement project in mine-tailing slopes will focus on the main factors dominating the stability of reinforced mine-tailing slope, so the governance for the reinforced mine-tailing slopes will become more reasonable, reliable and economical.

\section{ORTHOGONAL DESIGN}

\section{A. Introduction to Orthogonal Design}

Using Orthogonal experimental design (hereinafter called as orthogonal method for short) method, multi-factor and multi-level test programs can be in a reasonable and scientific arrangement and get reliable and convincing outcomes with a few numbers of tests. The orthogonal design first determines the factors influencing relevant indicators, then initially combines the orthogonal table to determine the level number and the level value of each factor. And later, determine the test plan based on orthogonal table, calculate and record the results and finally make reasonable analysis.

\section{B. The Determination of the Orthogonal Factor Level Table}

As for the mine-tailing slopes with geogrid reinforcement, from the perspective of engineering project, this paper mainly considers five factors: geogrid laying length (L), geogrid laying distance $(D)$, geogrid laying angle $(\theta)$, geogrid tensile strength $(\mathrm{T})$ and geogrid modulus (E) (hereinafter referring to: laying length, laying distance, laying angle, tensile strength and geogrid modulus for short). And then this study makes orthogonal analysis on the 5 factors with 5 levels, totally 25 kinds of cases. Besides, because the mine-tailing deposition sites always have a certain slope gradient smaller than $5 \%$, this paper takes into account four levels from $1 \% \sim 5 \%$. The tensile strength is based on the "Geogrid (GB17689-2008)", taking $50 \mathrm{KN} / \mathrm{m}, 80 \mathrm{KN} / \mathrm{m}, 120 \mathrm{KN} / \mathrm{m}, 160 \mathrm{KN} / \mathrm{m}, 200 \mathrm{KN} / \mathrm{m}$ as the five levels. Under the supposition that the deformation of grids is within its elastic range, the value of modulus is in the range of $0.5 \mathrm{GP}$ to $15 \mathrm{GPa}$. The level of each factor can be seen in TABLE 1 which selects the orthogonal table L25 (56) to arrange for orthogonal test programs.(the 6th column is an empty column, so it is omitted in TABLE 3) 
TABLE I. THE FACTOR AND THE FACTOR LEVEL

\begin{tabular}{|c|c|c|c|c|c|}
\hline \multirow[b]{2}{*}{$\begin{array}{l}\text { le } \\
\text { ve } \\
\text { l }\end{array}$} & \multicolumn{5}{|c|}{ The factors } \\
\hline & $\begin{array}{c}\text { laying } \\
\text { length } \\
L /(m) \\
\end{array}$ & $\begin{array}{c}\text { laying } \\
\text { spacing } \\
d /(m)\end{array}$ & $\begin{array}{c}\text { laying } \\
\text { angle } \\
\theta /(\%) \\
\end{array}$ & $\begin{array}{c}\text { tensile } \\
\text { strength } \\
T /(K N / m) \\
\end{array}$ & $\begin{array}{c}\text { grid } \\
\text { modulus } \\
\text { E/(GPa })\end{array}$ \\
\hline 1 & 80 & 1 & 1 & 50 & 0.5 \\
\hline 2 & 100 & 2 & 2 & 80 & 4 \\
\hline 3 & 120 & 3 & 3 & 120 & 7.5 \\
\hline 4 & 140 & 4 & 4 & 160 & 11 \\
\hline 5 & 160 & 5 & 5 & 200 & 15 \\
\hline
\end{tabular}

\section{THE Establishment OF Finite ElEMENT Models}

\section{A. Finite Element Calculation Model}

The mine-tailing slope selected in this paper is 58-metre high, and the slope is uniformly distributed in 1:3. Mine-Tailing components are macroscopically divided into four layers shown in FIGURE1. From the bottom to the top, they are tail clay, tail silty clay, tail powder silt and tail silt layer, whose model parameters are shown in Table 2. To establish the plane-strain model of finite elements, the left-and-right side should be under the horizontal constraint and the model bottom needs fixed constraint. The soil constitutive model is Mohr-Coulomb plasticity model and employs asymmetric algorithm to calculate in the analysis step. The grid partition adopts neutral axis algorithm and the soil-body model is divided into 6478 nodes and 6716 element by employing the strain element CPE4. The lattice only bears the truss element T2D2 and is divided in accordance with the seed size 5. The grid partition is shown in FIGURE 2. Moreover, initial conditions are added into the study to realize the calculation on the safety factor of the reinforced mine-tailing slope by the finite-element strength reduction method $[14,15]$.

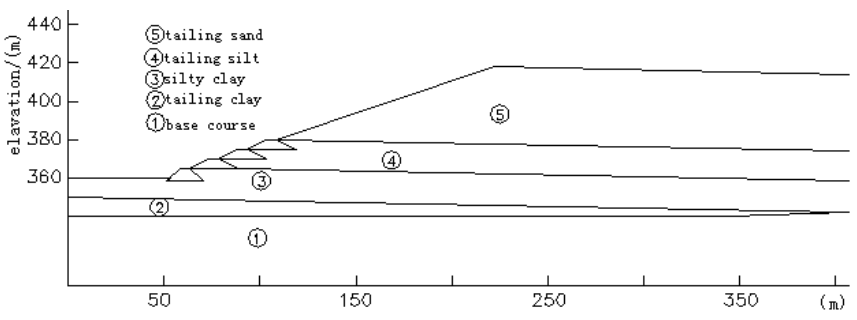

FIGURE I. THE DISTRIBUTION OF MINE TAILING

TABLE II. THE MOHR-COULOMB PARAMETERS OF MINE TAILING

\begin{tabular}{|l|l|l|l|l|l|}
\hline $\begin{array}{l}\text { material } \\
\text { parameter } \\
\mathrm{s}\end{array}$ & $\begin{array}{l}\text { densit } \\
\mathrm{y} /(\times 1 \\
0^{3} \mathrm{Kg} / \\
\left.\mathrm{m}^{3}\right)\end{array}$ & $\begin{array}{l}\text { Elasticity } \\
\text { Modulus } \\
\mathrm{E} /(\mathrm{MPa})\end{array}$ & $\begin{array}{l}\text { Pois } \\
\text { son's } \\
\text { ratio } \\
\mu\end{array}$ & $\begin{array}{l}\text { Internal } \\
\text { friction } \\
\text { angle } \\
\varphi /\left(^{\circ}\right)\end{array}$ & $\begin{array}{l}\text { Cohesi } \\
\text { on } \\
\mathrm{C} /(\mathrm{KPa} a \\
)\end{array}$ \\
\hline $\begin{array}{l}\text { tailing } \\
\text { sand }\end{array}$ & 2.04 & 90.20 & 0.3 & 28 & 10 \\
\hline tailing silt & 2.08 & 34.44 & 0.35 & 26 & 12 \\
\hline silty clay & 2.00 & 31.16 & 0.2 & 16 & 14 \\
\hline $\begin{array}{l}\text { tailing } \\
\text { clay }\end{array}$ & 1.95 & 22.14 & 0.25 & 10 & 14 \\
\hline
\end{tabular}

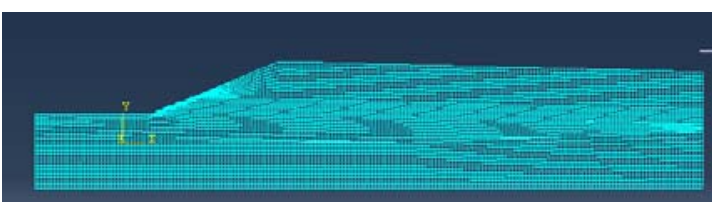

FIGURE II. THE GRID PARTITION FINITE ELEMENT

\section{A. Slope Stability Calculation Method}

The basic principle of the strength-reducing method is to gradually reduce the cohesive force $\mathrm{C}$ and the internal friction angle $\varphi$ of soil's shear strength index. And the reduction factor Fz corresponding to the critical state is a tentative safety factor For the Mohr-Coulomb plasticity, the shear strength parameter reduction model is expressed as:

$$
\begin{gathered}
C_{\mathrm{m}}=C / F_{\mathrm{z}} \\
\varphi_{m}=\arctan \left(\tan \varphi / F_{z}\right)
\end{gathered}
$$

In the formula: $\mathrm{C}$ is the cohesion of the soil; $\mathrm{Cm}$ is the cohesion of the soil after adjustment; $\Phi$ refers to the internal friction angle; $\Phi \mathrm{m}$ refers to the internal friction angle after adjustment; Fz is the strength reduction factor [5]; Because the reinforced slope is different from the pure soil slope, the criterion of the slope stability is based on the displacement inflection point combined with the tensile strength of the geogrid. Therefore, the author first employs the finite element strength-reducing method, regards the inflection point of featuring point's displacement as a criterion to get the reduction factor $\mathrm{Fz}$, and then finds out the corresponding reduction factor $\mathrm{FT}$ when the geogrid reaches the tensile strength. Subsequently, picking out the smaller one of $\mathrm{Fz}$ and FT as the final safety factor of stability F, and finally makes a variance analysis on the results of the finite element.

\section{ORThogonal Design CALCULATiOn Results AND VARIANCE ANALYSIS}

\section{A. Orthogonal Design Calculation Program and Results}

The plan of Orthogonal Experimental Design and the corresponding results of finite element strength reduction method are shown in TABLE 3.

TABLE III. THE PLAN AND RESULT OF ORTHOGONAL DESIGN

\begin{tabular}{|c|c|c|c|c|c|c|c|c|c|}
\hline $\begin{array}{c}\mathbf{p l} \\
\mathbf{a n}\end{array}$ & $\mathbf{L}$ & $\mathbf{d}$ & $\boldsymbol{\theta}$ & $\mathbf{T}$ & $\mathbf{E}$ & $\begin{array}{c}\mathbf{b l a} \\
\mathbf{n k}\end{array}$ & $\mathbf{F}_{\mathbf{Z}}$ & $\mathbf{F}_{\mathbf{T}}$ & $\mathbf{F}$ \\
\hline $\mathbf{1}$ & 80 & 1 & 1 & 50 & 0.5 & 1 & 1.131 & 1.158 & 1.131 \\
\hline $\mathbf{2}$ & 80 & 2 & 2 & 80 & 4 & 2 & 1.153 & 1.153 & 1.153 \\
\hline $\mathbf{3}$ & 80 & 3 & 3 & 120 & 7.5 & 3 & 1.159 & 1.153 & 1.153 \\
\hline $\mathbf{4}$ & 80 & 4 & 4 & 160 & 11 & 4 & 1.157 & 1.153 & 1.153 \\
\hline $\mathbf{5}$ & 80 & 5 & 5 & 200 & 15 & 5 & 1.153 & 1.153 & 1.153 \\
\hline $\mathbf{6}$ & 100 & 1 & 2 & 120 & 11 & 5 & 1.211 & 1.204 & 1.204 \\
\hline $\mathbf{7}$ & 100 & 2 & 3 & 160 & 15 & 1 & 1.189 & 1.179 & 1.179 \\
\hline $\mathbf{8}$ & 100 & 3 & 4 & 200 & 0.5 & 2 & 1.135 & 1.179 & 1.135 \\
\hline
\end{tabular}




\begin{tabular}{|c|c|c|c|c|c|c|c|c|c|}
\hline $\mathbf{9}$ & 100 & 4 & 5 & 50 & 4 & 3 & 1.144 & 1.141 & 1.141 \\
\hline $\mathbf{1 0}$ & 100 & 5 & 1 & 80 & 7.5 & 4 & 1.144 & 1.141 & 1.141 \\
\hline $\mathbf{1 1}$ & 120 & 1 & 3 & 200 & 4 & 4 & 1.293 & 1.254 & 1.254 \\
\hline $\mathbf{1 2}$ & 120 & 2 & 4 & 50 & 7.5 & 5 & 1.157 & 1.154 & 1.154 \\
\hline $\mathbf{1 3}$ & 120 & 3 & 5 & 80 & 11 & 1 & 1.157 & 1.154 & 1.154 \\
\hline $\mathbf{1 4}$ & 120 & 4 & 1 & 120 & 15 & 2 & 1.157 & 1.154 & 1.154 \\
\hline $\mathbf{1 5}$ & 120 & 5 & 2 & 160 & 0.5 & 3 & 1.132 & 1.163 & 1.132 \\
\hline $\mathbf{1 6}$ & 140 & 1 & 4 & 80 & 15 & 3 & 1.195 & 1.178 & 1.178 \\
\hline $\mathbf{1 7}$ & 140 & 2 & 5 & 120 & 0.5 & 4 & 1.128 & 1.200 & 1.128 \\
\hline $\mathbf{1 8}$ & 140 & 3 & 1 & 160 & 4 & 5 & 1.194 & 1.193 & 1.193 \\
\hline $\mathbf{1 9}$ & 140 & 4 & 2 & 200 & 7.5 & 1 & 1.192 & 1.191 & 1.191 \\
\hline $\mathbf{2 0}$ & 140 & 5 & 3 & 50 & 11 & 2 & 1.144 & 1.128 & 1.128 \\
\hline $\mathbf{2 1}$ & 160 & 1 & 5 & 160 & 7.5 & 2 & 1.351 & 1.304 & 1.304 \\
\hline $\mathbf{2 2}$ & 160 & 2 & 1 & 200 & 11 & 3 & 1.254 & 1.241 & 1.241 \\
\hline $\mathbf{2 3}$ & 160 & 3 & 2 & 50 & 15 & 4 & 1.154 & 1.128 & 1.128 \\
\hline $\mathbf{2 4}$ & 160 & 4 & 3 & 80 & 0.5 & 5 & 1.128 & 1.159 & 1.128 \\
\hline $\mathbf{2 5}$ & 160 & 5 & 4 & 120 & 4 & 1 & 1.166 & 1.166 & 1.166 \\
\hline
\end{tabular}

\section{B. Variance Analysis}

In this paper, variance analysis method is employed to analyze these results and the basic method of variance analysis shows as follows:

$$
\begin{aligned}
& P=\frac{1}{\mathrm{n}}\left(\sum_{i=1}^{n} y_{i}\right)^{2} \\
& R_{k}=\frac{1}{a_{k}} \times \sum_{j}^{a_{k}} y_{j}^{2} \\
& Q_{k}=R_{k}-P \\
& S_{k}=\frac{Q_{k}}{f_{k}} \\
& S_{\Delta e}=\frac{Q_{\Delta e}}{f_{\Delta e}} \\
& F_{\Delta k}=\frac{S_{k}}{S_{\Delta e}}
\end{aligned}
$$

Where $y_{i}$ is the result of the $i$ th solution, $y_{j}^{2}$ is the square of the $i$ th level corresponding to a factor, $n$ is the total number of programs equal to $25, a_{k}$ is the number of the factor equal to $5, Q_{k}$ is the deviation of the factor , $f_{k}$ is the degree of freedom of the factor equal to $a_{k}-1=$ 4; the statistic $Q_{\Delta e}$ is the sum of squared deviations of the total error; $f_{\Delta e}$ is the total degree of freedom of the error equal to
8.

Calculate the sum of squared deviations (squared deviations). The squared deviations $Q_{k}(\mathrm{k}=\mathrm{L}, \mathrm{d}, \theta, \mathrm{T}, \mathrm{E})$ and the error of the deviation $Q_{e}(\mathrm{k}=\mathrm{e})$ of each factor are calculated using Eqs. (3), (4) and (5). Comparing the size of squared deviation of each factor, we can distinguish the relative size of each factor sensitivity, that is, the larger the square of deviation, the more sensitive the factors.

Calculate the variance estimate. In this paper, as $Q_{\theta}$ is smaller than ${ }^{Q_{e}}, Q_{\theta}$ can be regarded as the sum of squares of errors, which is written into ${ }_{e}$, and the corresponding degree of freedom $f_{\theta}$ is also incorporated into $f_{\Delta e}$, using formula (6) and (7) to calculate the variance estimates of the factors and errors.

Using formula (8) to calculate $F$ value.

$\mathrm{F}$ test. Statistically, the $\mathrm{F}$ value of each factor was compared with the critical value $F_{\Delta k}$ as the criterion for judging the significance. This test was called $F$ test. When the $F_{\Delta k}$ value is greater than $F_{\alpha}\left(f_{k}, f_{\Delta e}\right)$, the test level $\alpha$ inferred that the role of the factor significantly; otherwise not significant. The significance level of $\mathrm{F}$ distribution is usually $0.01,0.025$ and 0.05 respectively, and the $F_{\alpha}\left(f_{k}, f_{\Delta e}\right)$ value of the three significant levels is determined by the $\mathrm{F}$ probability distribution statistics table. By comparing the calculated $F_{\Delta k}$ value with $F_{\alpha}\left(f_{k}, f_{\Delta e}\right)$, the effects of the factors were divided into 4 significant level levels [4]:

If $\mathrm{F} \geqslant \mathrm{F} 0.01$, it is highly significant effect, denoted as "***";

If $\mathrm{F} 0.01>\mathrm{F} \geqslant \mathrm{F} 0.025$, the significant effect is denoted as $" * * "$.

If $\mathrm{F} 0.025>\mathrm{F} \geqslant \mathrm{F} 0.05$, for the impact is not very significant, recorded as "*";

If $\mathrm{F}<\mathrm{F} 0.05$, there is no significant effect, denoted as " $\times$ ".

TABLE IV. THE RESULT OF REMARKABLE TEST

\begin{tabular}{|c|c|c|l|c|c|}
\hline $\begin{array}{c}\text { sour } \\
\text { ce }\end{array}$ & $\begin{array}{c}\text { Square } \\
\text { Sum(Q) }\end{array}$ & $\begin{array}{c}\text { Freedom } \\
\text { Degree(f) }\end{array}$ & $\begin{array}{c}\text { Variance } \\
\text { Estimator(S) }\end{array}$ & $\begin{array}{c}\mathrm{F} \\
\text { Value }\end{array}$ & $\begin{array}{c}\text { Signifi } \\
\text { cance }\end{array}$ \\
\hline $\mathrm{L}$ & 0.00551 & 4 & 0.001378 & 6.407 & $*$ \\
\hline $\mathrm{d}$ & 0.01582 & 4 & 0.003955 & 18.395 & $* * *$ \\
\hline$\theta$ & 0.00117 & 4 & 0.000293 & - & $\times$ \\
\hline $\mathrm{T}$ & 0.01321 & 4 & 0.003303 & 15.360 & $* * *$ \\
\hline $\mathrm{E}$ & 0.01069 & 4 & 0.002673 & 12.430 & $* *$ \\
\hline $\mathrm{e}$ & 0.00055 & 4 & 0.000138 & & \\
\hline$\Delta \mathrm{e}$ & 0.00172 & 8 & 0.000215 & & \\
\hline
\end{tabular}

According to the analytic steps introduced before in this paper and by comparing the sum of square of each factor in TABLE 4, a conclusion can be drawn that the sensitivity of the five influential factors is as follow in order of most to least: laying distance (D), tensile strength (T), geogrid modulus $(E)$, laying length (L), laying angle $(\theta)$. Based on steps above, a remarkable test has been made on the calculation results (TABLE 3) obtained from orthogonal method without considering the interaction among all the factors. And it can be 
seen clearly in the orthogonal table L25(56). In this table, each column has the freedom degree four and the empty column is designed as random error line. Amid it, the sum of deviance square of the laying angle $(\theta)$ is less than that of the random errors in average. And the former is integrated with the latter ${ }_{\text {as }} Q_{\Delta e}$, so is its freedom degree added to the freedom degree of errors. This table shows the laying angle $(\theta)$ has no striking influence on the safety and stability of the reinforced slope. Take the significance level of the $\mathrm{F}$ distribution $\alpha$ as 0.01 , $0.025,0.05$. Based on the reference for the F distribution table, it can be known that: F0.01 $(4,8)=14.80 ;$ F0.025 $(4,8)=8.9$; F0.05 $(4,8)=6.0$; In the light of the classification method of significance level, the results can be classified in detail shown in TABLE 4. Through the variance analysis on the five factors, the results gained from the remarkable test show that laying distance (D) and tensile strength (T) both have very remarkable influence on stability and safety factor and geogrid modulus (E) comes second, while laying length (L) only shows a little and laying angle $(\theta)$ little. In addition, by comparing the values of $\mathrm{F}$ one another in table 4 , it can be noted that the order of sensitivity is consistent with that of their significance.

\section{V.CONCLUSION}

To effectively enhance the stability and safety of the reinforced slope in mine tailings, this paper adopts the orthogonal method to make a variance analysis on the five factors influencing the geogrid reinforcement on slope safety and stability of mine tailings, which has drawn the following conclusions:

a) The results show the sensitivity of all influential factors on stability and safety as follow in order of most to least: laying distance (D), tensile strength (T), geogrid modulus (E), laying length $(\mathrm{L})$, laying angle $(\theta)$. The remarkable test show that laying distance (D) and tensile strength (T) both have very remarkable influence on stability and safety factor and geogrid modulus (E) comes second, while laying length (L) only shows a little and laying angle $(\theta)$ little.

b) The study has shown that the geogrid laying angle $(\theta)$ less than $5 \%$ has no significant effect on the geogrid reinforcement projects, which means when the slope angle of a deposition site is not more than $5 \%$, it is the influence of geogrid laying angle $(\theta)$ on the stability and safety of reinforced slope that can be ignored .

This paper employs the orthogonal method to analyze the parameters related to the slope reinforcement in mine tailing. The results obtained in this study have greatly reflected the effects of reinforcement material parameters on safety factors, which will offer a reference to the projects of geogrid reinforcement in mine-tailing slopes.

\section{ACKNOWLEDGEMENTS}

I would like to extend my sincere gratitude to Chunming QI and Chunlong NIE, for them instructive advice and useful suggestions on my thesis. This study was financially supported by the Natural Science Foundation of Hunan Province (11JJ6045).

\section{REFERENCE}

[1] Fazheng WEI. Reinforcement practices in Kinmen and Matsu lead-zinc tailings [J].Mining Safety \& Environmental Protection, 2008,35(4):47-51.

[2] Zuoan WEI, Jiajun XU, Yulong CHEN, dandan ZHANG. reinforcement Method of Both Ends Scroll Geosynthetics in Tailings Dam[J]. Journal of Northeastern University (Natural Science), 2014, 35(06):880-884.

[3] Yishu ZHAO, Xiaofei JING, Xiao ZHOU, Zhiyong CAI, Kehui LIU. Experimental study on blocking action of bar strip on tailings dam overtopping[J]. China Safety Science Journal, 2016, 26(1): 94-99.

[4] B. H. Wang, Y. Jin, and Y. G. Luo. Parametric optimization of EQ6110HEV hybrid electric bus based on orthogonal experiment design $[\mathrm{J}]$. International Journal of Automotive Technology, 2010, Vol.11 (1), pp.119-125.

[5] Kang FEI, Jianwei ZAHNG. Abaqus application in geotechnical engineering [M].Beijing: China Water \& Power Press, 2013.

[6] Lin HANG, Xiong WEI, and Cao PING. Stability of soil nailed slope using strength reduction method[J]. European Journal of Environmental and Civil Engineering, 2013, Vol.17 (9), pp.872-885. 